\title{
Pharmacoeconomics of antidepressants in moderate-to-severe depressive disorder in Colombia
}

\author{
Márcio Machado, ${ }^{1}$ Monica Maria Lopera, ${ }^{2}$ Jorge Diaz-Rojas, ${ }^{3}$ \\ Luis Eduardo Jaramillo, ${ }^{2}$ Thomas Ray Einarson, ${ }^{1}$ \\ and The Universidad Nacional de Colombia Pharmacoeconomics Group ${ }^{3}$
}

Suggested citation Machado M, Lopera MM, Diaz-Rojas J, Jaramillo LE, Einarson TR, The Universidad Nacional de Colombia Pharmacoeconomics Group. Pharmacoeconomics of antidepressants in moderate-to-severe depressive disorder in Colombia. Rev Panam Salud Publica. 2008;24(4):233-9.

ABSTRACT Objective. To compare three antidepressant drugs from different classes used in treating moderate-to-severe major depressive disorder (MDD) in Colombian adults.

Methods. Based on expert input, a decision-tree model was adapted for Colombia to analyze data over 6 months from the government-payer perspective. The cost-effectiveness of amitriptyline, fluoxetine, and venlafaxine was determined. The clinical outcome was remission of depression (a score $\leq 7$ on the Hamilton Depression [HAM-D] scale or $\leq 12$ on the MontgomeryAsberg Depression Rating Scale [MADRS]) after 8 weeks of treatment. Clinical data were obtained from the literature and costs from standard Colombian price lists. One-way and multivariate sensitivity analyses tested model robustness.

Results. Costs per patient (in 2007 US\$) for treatment were: venlafaxine, \$1 618; fluoxetine, \$1 207; and amitriptyline, \$1 068. Overall remission rates were $73.1 \%, 64.1 \%$, and $71.3 \%$, respectively. Amitriptyline dominated fluoxetine (i.e., it had lower costs and higher outcomes). The incremental cost-effectiveness ratio (ICER) of venlafaxine over amitriptyline was US\$ 31 595. The acquisition price of venlafaxine was the model's cost driver, comprising $53.4 \%$ of the total cost/patient treated, compared with $18.5 \%$ and $24.8 \%$ for fluoxetine and amitriptyline, respectively. For the others, hospitalization comprised the major cost $(72.1 \%$ and $65.2 \%$, respectively). Probabilistic (Monte Carlo) sensitivity analysis confirmed the original findings of the pharmacoeconomic model.

Conclusions. Amitriptyline is cost-effective in comparison to fluoxetine and venlafaxine in Colombia. However, the cost of venlafaxine was estimated for the brand-name product, as generics were not currently available. These cost-effectiveness results can be substantially affected by the presence of generics or drug cost regulations.

Key words Pharmaceutical economics, antidepressant agents, decision support techniques, Colombia.

Leslie Dan Faculty of Pharmacy, University of Toronto, Toronto, Ontario, Canada. Send correspondence and reprint requests to: Márcio Machado, Leslie Dan Faculty of Pharmacy, University of Toronto-Pharmacy Administration, 144 College Street, Toronto, Ontario M5S 3M2,
Canada; telephone: (416) 946-3700; fax: (416) 9463719; e-mail: m.machado@utoronto.ca

2 Facultad de Medicina, Universidade Nacional de Colombia, Bogotá, Colombia.

3 Departamento de Farmacia, Universidade Nacional de Colombia, Bogotá, Colombia.
Depression is a major health problem worldwide, ranking fourth globally as a health problem $(1,2)$. Latin America is no exception, and the problem may be even worse in that part of 
the world. Kohn and associates (3) estimated that the 1-year prevalence of depression in Latin America was $4.9 \%$. Muñoz and colleagues (4) further reported that $72.6 \%$ of nearly 1000 patients surveyed reported painful somatic symptoms. These somatic symptoms had a significantly deleterious effect on quality of life. In 2004, in Colombia, a study by Gómez-Restrepo et al. reported a $10 \%$ prevalence rate of patients with any depressive episode in the previous 12 months with over $50 \%$ of these patients with moderateto-severe disease (5).

Unfortunately, there is a wide treatment gap, according to Kohn and coworkers $(3,6)$. They found a mean treatment gap for depression of $56.3 \%$, which represents the proportion of patients for whom treatment is available yet remain untreated. Therefore, this disease is widespread and problematic for sufferers.

At the same time, increasing demands for funds requires that payers make choices between drugs. These drugs may vary with respect to their clinical profiles, as well as their costs. Pharmacoeconomics has emerged as an approach to aid in decision-making that simultaneously takes into account both of these aspects. By thoroughly analyzing the data, decision-makers can make informed judgments concerning the suitability of funding individual drugs or classes of drugs.

The situation in South America is probably more acute than in more developed nations. With limited funding and ever-increasing costs of care, the countries in this region would seem ideal environments in which to introduce pharmacoeconomics. Most pharmacoeconomic studies on antidepressants have been conducted in Europe and North America, however, with only a few analyses of this type performed in South America $(7,8)$. Only one study (in Venezuela) was found evaluating antidepressants (9). There were three existing pharmacoeconomic studies available in Colombia (7). Two of the three Colombian studies were cost-effectiveness analyses (total anesthesia versus inhaled anesthesia, and campaign versus routine infant immunization), and one was a cost-benefit analysis (vaccination versus no influenza vaccination) (7). To the best of the authors' knowledge, prior to this study, no pharmacoeconomic analysis of antidepressants has been conducted in Colombia.

The objective of this study was to compare the cost-effectiveness of three antidepressant drugs from different classes used in treating moderateto-severe major depressive disorder (MDD) in Colombian adults.

\section{MATERIALS AND METHODS}

The intended audience for this research was the government, drug plans, and psychiatric healthcare professionals within Colombia. The study was conducted from a governmentpayer perspective and considered all direct costs of treatment over a 6month time horizon (indirect costs were not included in the analysis). The 6-month time frame was selected because it matched the parameters of available, acceptable data and allowed sufficient time for clinical effects to manifest.

The target population was adults (male and female) aged $\geq 18$ suffering from their first episode of moderateto-severe MDD as defined by the Diagnostic and Statistical Manual, Version 4 (DSM-IV) (10). The study sample was limited to those with no other serious comorbidities who were not taking any drugs that could interfere with depression diagnosis or treatment (occasional hypnotics or anti-anxiety agents were permitted). Qualifying episodes of MDD (moderate to severe) were determined by a score $\geq 15$ on the Hamilton Depression (HAM-D) scale (11) or $\geq 18$ on the Montgomery-Åsberg Depression Rating Scale (MADRS) (12).

Amitriptyline, fluoxetine, and venlafaxine were selected for the study as respective representative examples of the three most prescribed classes of antidepressant drugs: tricyclic antidepressants (TCAs), selective serotonin reuptake inhibitors (SSRIs), and selective serotonin-norepinephrine reup- take inhibitors (SNRIs). All drugs were administered on a daily basis and in standard therapeutic doses.

A cost-effectiveness model based on a previously published and validated analytic decision-tree (13) was used to compare the direct costs and outcomes of the three drugs. Expert opinion from a clinical/academic psychiatrist practicing and teaching in Colombia was used to guide all aspects of patient management. Clinical pathways along the decision tree were verified for the country, as well as for medical resources utilized in the course of treatment.

Details of model pathways and analytic procedures are described elsewhere (13). In summary, patients were followed for 4-6 weeks of initial treatment to determine the presence of adverse drug reactions (ADRs) or lack of [therapeutic] efficacy (LoE). For each initial follow-up, physician visits and drug treatments were recorded as "medical resource used." If treatment failures were observed, patients underwent dose titration or switched antidepressants (assuming a 50/50 chance for each choice) for an additional 4-6 weeks, using fluoxetine as a secondary treatment following venlafaxine and amitriptyline and amitriptyline as a secondary treatment following fluoxetine. Patients with therapeutic failure to primary and secondary drug treatments were hospitalized for a period of 30 days. When hospitalized, patients underwent cognitive behavior therapy (CBT) and electroconvulsive therapy (ECT). Following hospitalization, patients were assumed to be in clinical remission. A decision tree representing the pharmacoeconomic model is presented in Figure 1.

Clinical model input data were derived from a previously published meta-analysis of the literature using only head-to-head trials between classes of antidepressants used to treat patients diagnosed with MDD (14). Clinical outcomes included "success" (i.e., remission), "ADRs dropout" (dropout due to adverse drug reactions), and "LoE dropout" (dropout due to lack of therapeutic efficacy). As previous research (14) found that seri- 
FIGURE 1. Analytical decision tree used for cost-effectiveness analysis of antidepressants for moderate-to-severe depressive disorder in Colombia, 2007a

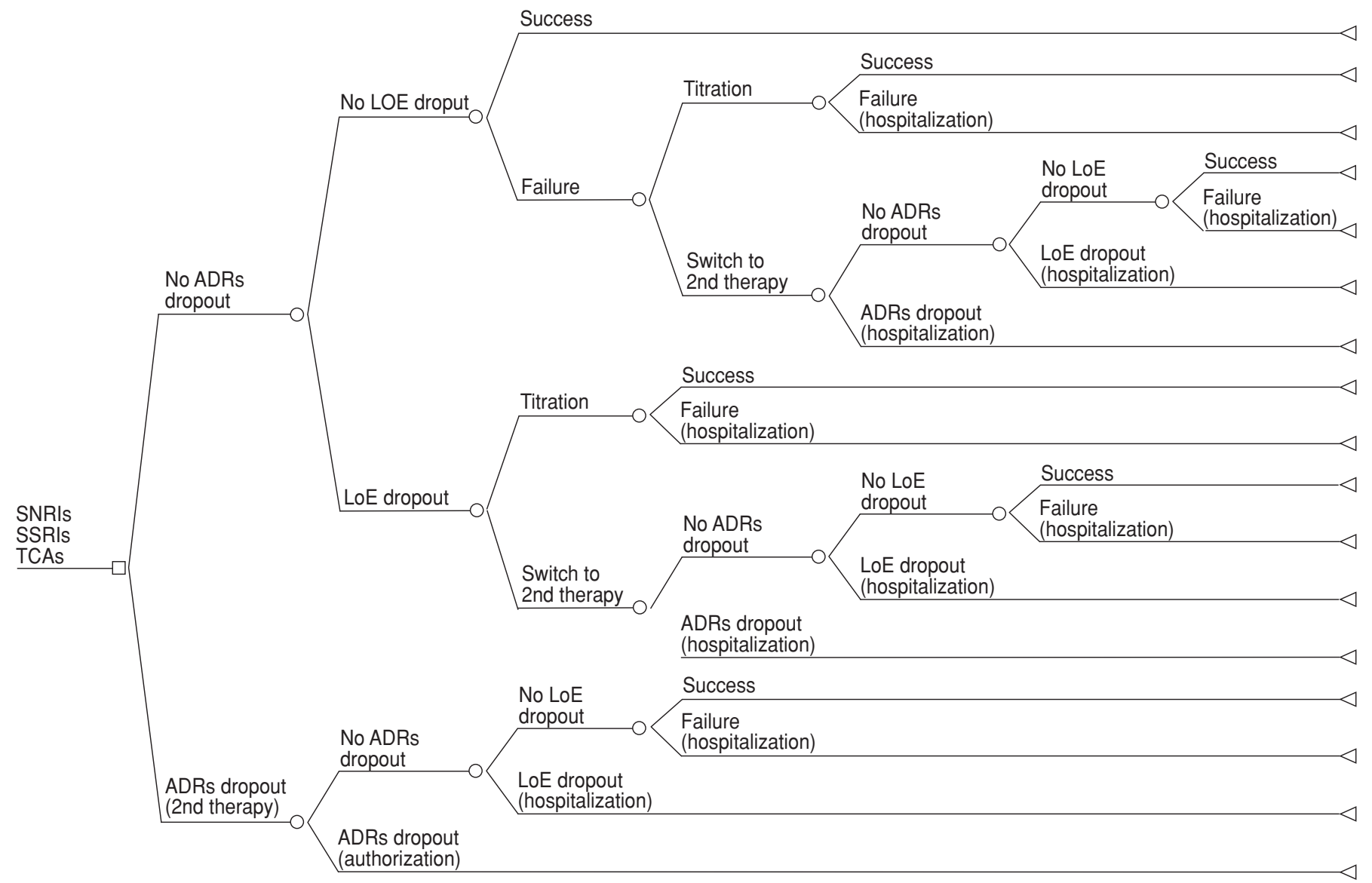

a ADRs: adverse drug reactions; LoE: lack of efficacy; SNRIs: selective serotonin and norepinephrine reuptake inhibitors (represented by venlafaxine); SSRIs: selective serotonin reuptake inhibitors (represented by fluoxetine); TCAs: tricyclic antidepressants (represented by amitriptyline).

ous adverse reactions to these drugs were uncommon and similar across classes, they were not considered in the analysis.

The outcome of interest was remission of symptoms, defined as a score of $\leq 7$ on the HAM-D scale (11) or $\leq 12$ on the MADRS (12) after 8 weeks of treatment. This outcome was selected as it best represents clinical resolution of the disease, which cannot be captured by other outcomes such as response (i.e., $50 \%$ decrease in scores) or differences between group means on depression scores (15). Health-related quality of life (HRQL), while considered an important aspect of MDD, was not assessed.

Costs for resources used were obtained from standard lists. Medical care, hospital costs, and laboratory fees were obtained from the 2005 government list (16). Drug costs were taken from a local supplier (17). Table 1 presents cost inputs for the pharmacoeconomic model. In all cases, the cost of the alternative with the lowest price was used. Because the model time horizon was less than one year, discounting was not applied. Costs were adjusted to current year exchange rates and presented in 2007 US\$ (US\$ $1=$ 2155 Colombian pesos).

The expected cost of each drug per patient treated was calculated, as well as the expected rate of success (i.e., remission). In the case of dominance (i.e., lower costs and higher effect), the expected cost per remission was calculated and compared across drugs. In the event of incremental costs with incremental benefits, the incremental cost-effectiveness ratio (ICER) was calculated in terms of the added cost per additional remission achieved by the more effective treatment.

To examine the robustness of the model, several one-way sensitivity analyses were calculated. Variables tested included drug costs, success rates, and dropout rates. A probabilistic, multivariate (Monte Carlo) sensitivity analysis was also conducted, varying all model inputs within their plausible ranges using different distribution patterns for a minimum of 10000 trial runs. This analysis produced an estimated mean expected cost and standard deviation (SD) for each drug across all likely scenarios 
TABLE 1. Cost inputs for the pharmacoeconomic analysis of antidepressants in Colombia, 2007

\begin{tabular}{|c|c|}
\hline Type of cost & $\begin{array}{l}\text { Unit cost }^{\mathrm{a}} \\
\text { (US\$) }\end{array}$ \\
\hline \multicolumn{2}{|l|}{ Medical care ${ }^{b}$} \\
\hline Hospitalization (per day) & 81 \\
\hline Physician visit & 11 \\
\hline Laboratory (initial regimen) & 5 \\
\hline Electroconvulsive therapy (per session) & 7 \\
\hline Psychotherapy (per session) & 11 \\
\hline \multicolumn{2}{|l|}{ Drugs $^{c}$} \\
\hline Venlafaxine & 30 \\
\hline Fluoxetine & 5 \\
\hline Amitriptyline & 5 \\
\hline
\end{tabular}

and allowed for statistical contrasting of results.

\section{RESULTS}

Venlafaxine had the highest cost per patient treated (US\$ 1 618), followed by fluoxetine (US\$ 1207 ) and amitriptyline (US\$ 1068 ). In the case of venlafaxine, the drug cost was the major driver for the model, comprising $53.4 \%$ of the total. However, for fluoxetine and amitriptyline, the drug cost represented only $18.5 \%$ and $24.8 \%$ of total costs, respectively. For fluoxetine and amitriptyline, costs associated with hospitalization constituted the major cost driver, representing $72.1 \%$ and $65.2 \%$ of their totals, respectively.
Clinical outcome rates (i.e., rates of remission), as determined from the pharmacoeconomic model, were $73.1 \%$ for venlafaxine, $71.3 \%$ for amitriptyline, and $64.1 \%$ for fluoxetine. Venlafaxine had the highest cost per remission (US\$ 2 215), followed by fluoxetine (US\$ 1882 ), and amitriptyline (US\$ 1 498).

In the model, fluoxetine was dominated by amitriptyline, as it had a higher cost and lower efficacy. It was therefore dropped from the analysis. When an ICER analysis was performed between venlafaxine and amitriptyline, the ICER was US\$ 31595 (i.e., one additional remission would cost an additional US\$ 31595 if amitriptyline were replaced by venlafaxine). Table 2 presents treatment costs, clinical efficacy, and cost-effectiveness ratios for antidepressants in Colombia.

In univariate sensitivity analyses of costs, it was determined that drug and hospitalization costs were not sensitive to reasonable variations in inputs. For example, in reducing venlafaxine's cost by $50 \%$, no changes were observed in the relative order of drugs with respect to their cost per remission (i.e., venlafaxine $>$ fluoxetine $>$ amitriptyline). The same was observed when hospitalization costs were increased by $50 \%$.

In break-even analyses, the pharmacoeconomic results were not sensitive to antidepressants' rates of clinical efficacy. To produce cost-effectiveness ratios equal to that of fluoxetine, the success rate of venlafaxine would have to increase by $25.5 \%$ (from $60.8 \%$ to $86.3 \%$ ), and to equal that of amitriptyline, it would need to increase by $34.7 \%$ (from $60.8 \%$ to $95.5 \%$ ). Both of those increased success rates lie outside of venlafaxine's $95 \%$ confidence interval (CI), as reported in the metaanalysis by Machado et al. (14). Similarly, the remission rates of fluoxetine would have to decrease from $41.1 \%$ to $20.2 \%$ and amitriptyline from $69.9 \%$ to $36.1 \%$ for the cost-effectiveness ratios to become equal. These values also fall outside of their reported 95\% CIs. Thus, results are robust against probable perturbations in these values.

Results from the Monte Carlo simulations were similar to the original findings of the pharmacoeconomic model. Figure 2 depicts a cost-effectiveness

TABLE 2. Overall results from pharmacoeconomic analysis of antidepressants in Colombia, 2007a

\begin{tabular}{|c|c|c|c|c|c|c|c|c|}
\hline \multirow[b]{2}{*}{ Drug } & \multicolumn{4}{|c|}{ Resource utilization costs per patient treated } & \multirow{2}{*}{$\begin{array}{c}\text { Total } \\
\text { (expected) } \\
\text { cost per } \\
\text { patient } \\
\text { treated } \\
(\cup S \$)^{d}\end{array}$} & \multirow{2}{*}{$\begin{array}{c}\text { Expected } \\
\text { success rate } \\
\text { (remission) } \\
(\%)\end{array}$} & \multirow{2}{*}{$\begin{array}{c}\text { Cost } \\
\text { per } \\
\text { success } \\
\text { (US\$) }\end{array}$} & \multirow[b]{2}{*}{$\begin{array}{l}\text { Cost- } \\
\text { effectiveness }\end{array}$} \\
\hline & $\begin{array}{l}\text { Hospitalization } \\
\text { (US\$) }\end{array}$ & $\begin{array}{c}\text { Physician care } \\
\text { (US\$) }\end{array}$ & $\begin{array}{l}\text { Drugs }^{b} \\
\text { (US\$) }\end{array}$ & $\begin{array}{l}\text { Otherc } \\
\text { (US\$) }\end{array}$ & & & & \\
\hline Venlafaxine & 654 & 73 & 864 & 28 & 1618 & 73.1 & 2215 & Dominated \\
\hline Amitriptyline & 696 & 71 & 265 & 36 & 1068 & 71.3 & 1498 & Dominante \\
\hline
\end{tabular}


cloud diagram comparing antidepressants. The average costs per patient treated were: US\$ 1622 (SD = US\$ 193) for venlafaxine, US\$ 1218 (SD = US\$ 170) for fluoxetine, and US\$ 1069 $(\mathrm{SD}=\$ 137)$ for amitriptyline. Average remission rates were: venlafaxine = $72.8 \%(\mathrm{SD}=6.6 \%)$, fluoxetine $=63.5 \%$ $(\mathrm{SD}=5.9 \%)$, and amitriptyline $=71.2 \%$ $(\mathrm{SD}=4.3 \%)$. The $50 \%$ probability of cost-effectiveness of venlafaxine over fluoxetine and amitriptyline corresponded to ICERs of US\$ 2456 and US\$ 2 155, respectively. Figure 3 shows a cost-effectiveness acceptability curve of venlafaxine over fluoxetine and amitriptyline.

\section{DISCUSSION}

Pharmacoeconomic evaluation showed that amitriptyline is cost-effective compared to fluoxetine and venlafaxine in Colombia. Amitriptyline dominated fluoxetine (i.e., it had lower costs and higher effect), and replacing amitriptyline with venlafaxine resulted in an ICER of US\$ 31595.

Differences in clinical outcomes as calculated in the pharmacoeconomic model were not considered clinically relevant. Differences in remission rates between venlafaxine and fluoxetine, and amitriptyline and fluoxetine, were less than $10 \%$ ( $9 \%$ and $7 \%$, respectively), which was considered the threshold for clinical relevance. Additionally, break-even analysis showed that cost-effectiveness ratios were not sensitive to variations in clinical outcomes.

In an analysis of extremes of clinical rates, using an upper limit of the $95 \%$ CI for venlafaxine and the lower limit for fluoxetine and amitriptyline, the overall results remained practically unchanged. The corresponding costeffectiveness ratios were: US\$ 1312 , US\$1 488, and US\$ 1274 for venlafaxine, fluoxetine, and amitriptyline, respectively. Additionally, when increasing the remission rate of venlafaxine, or decreasing those of fluoxetine and amitriptyline, the resulting values fell outside of their corresponding $95 \%$ CIs, which indicate the ab-
FIGURE 2. Cost-effectiveness cloud diagram of antidepressants in Colombia, 2007 (costs reported in 2007 US\$ [US\$1 = 2155 Colombian pesos])

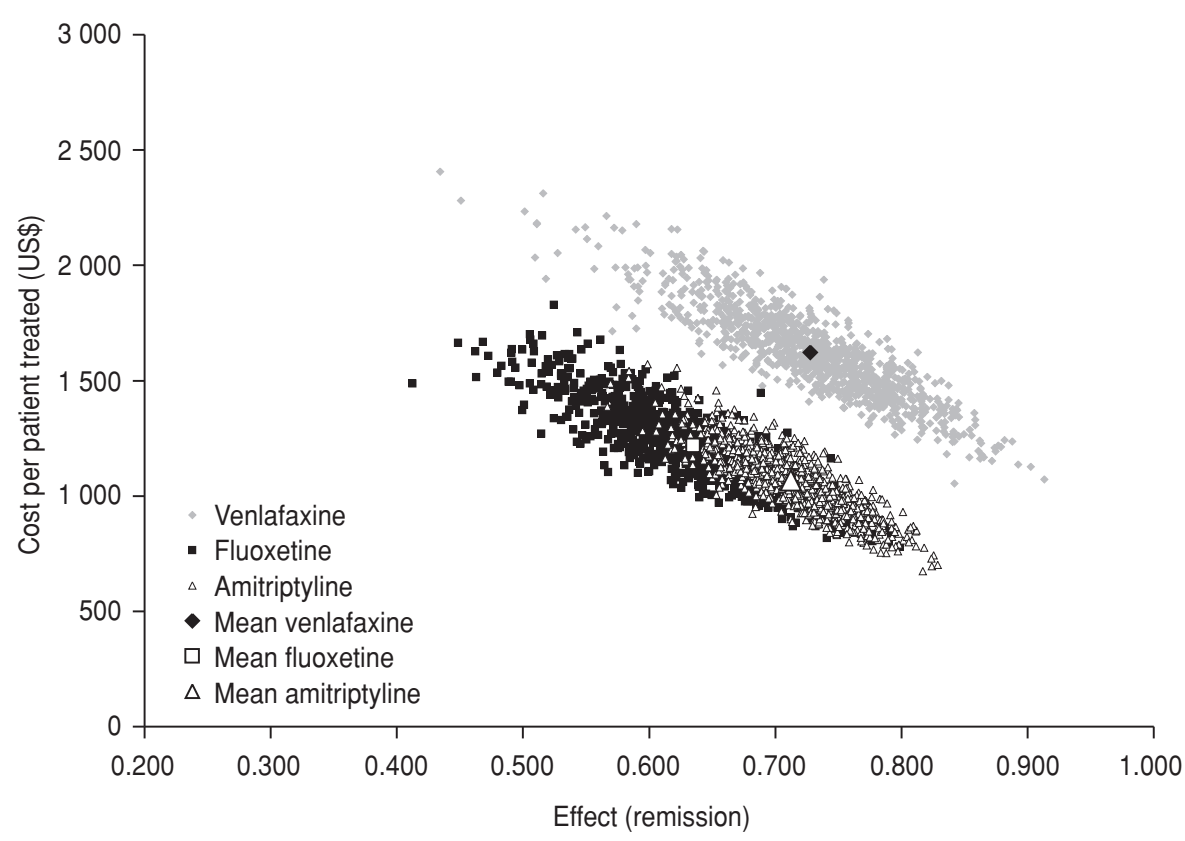

FIGURE 3. Cost-effectiveness acceptability curve of venlafaxine over fluoxetine and amitriptyline in Colombia, 2007 (costs reported in 2007 US\$ [US\$ 1 = 2155 Colombian pesos])

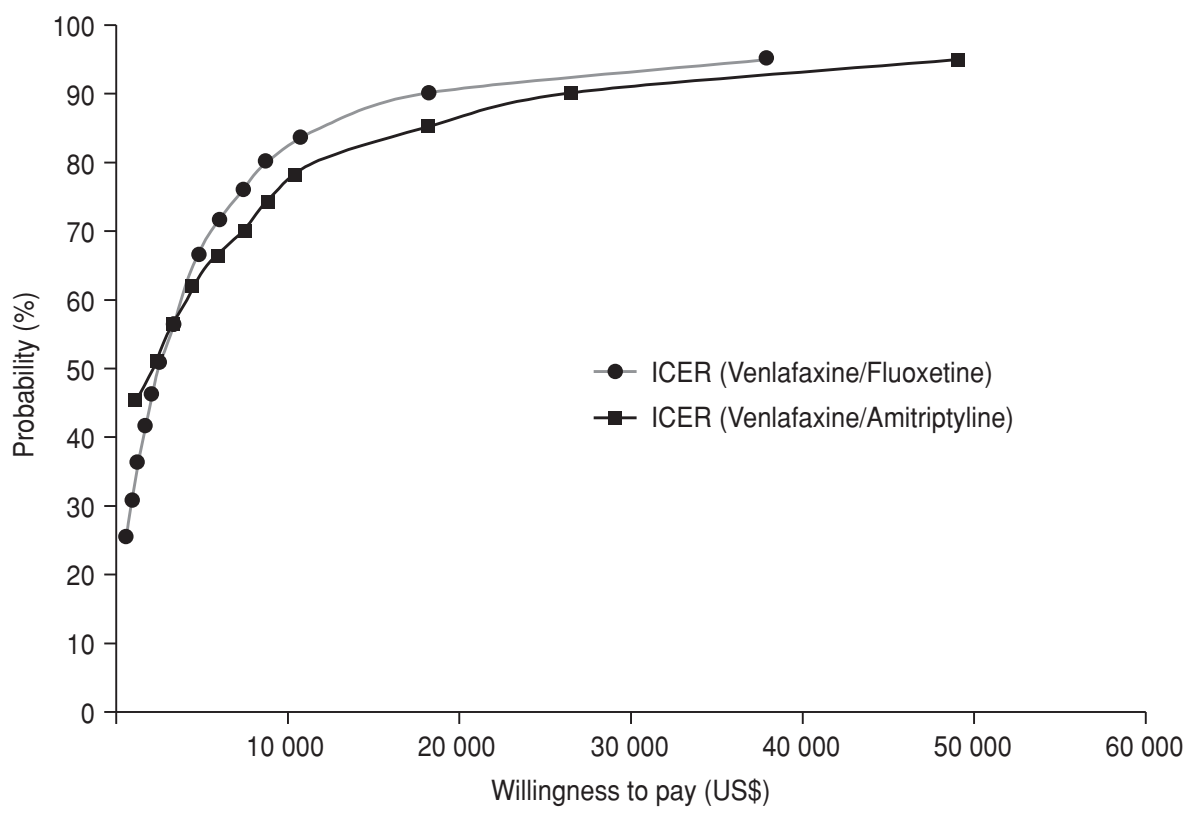

sence of sensitivity. In univariate sensitivity cost analyses, it was found that by reducing drug costs or by increasing hospitalization costs by $50 \%$, the overall cost-effectiveness ratio positions (amitriptyline $<$ fluoxetine $<$ venlafaxine) remained unchanged.
However, the corresponding ICERs of venlafaxine over fluoxetine and amitriptyline (when venlafaxine's cost is reduced by 50\%) were US\$ 491 and US\$ 10 508, respectively. In that scenario, the ratios achieved lower values, and venlafaxine became cost- 
effective compared to fluoxetine but not to amitriptyline.

Monte Carlo sensitivity analysis showed that the model is robust to variations across multiple parameter inputs. In other words, the overall results of the pharmacoeconomic model remained unchanged and costeffectiveness ratios maintained their relative positions after multivariate analysis.

Similar pharmacoeconomic analyses have been performed in other countries $(8,13,17,18)$ but yielded different results. In almost all studies, venlafaxine or SNRIs were cost-effective compared to SSRIs and TCAs $(9,13,18)$. A recent Brazilian study concluded that SNRIs, SSRIs, and TCAs had no significant differences in cost-effectiveness results (19). In that study, even though SNRIs reported dominance (lower costs and higher effect), the results overlapped within their respective 95\% CIs when tested using multivariate sensitivity analyses, and therefore no statistically significant difference was achieved. Therefore, venlafaxine was not clearly superior to the other drugs.

Further differences in published pharmacoeconomic studies of antidepressants and the results of this study lie in different cost inputs for the pharmacoeconomic model. For example, the estimated cost of hospitalization per day in Brazil (19) is almost four times greater than that in Colombia (US\$ 293 and US\$ 81, respectively). In Canada (13) and Venezuela (8), where cost-effectiveness results favored venlafaxine, the cost of hospitalization due to major depression can be as high as $8-15$ times the Colombian cost. In this type of scenario, hospitalization costs become cost drivers and drug costs have minimal impact. In Colombia, the estimated cost of hospitalization per patient treated was lower for venlafaxine compared to fluoxetine and amitriptyline (US\$ 654 versus US\$ 870 and US\$ 696, respectively). However, hospitalization costs represented only $40.4 \%$ of total costs attributed to venlafaxine and did not drive its costs. Therefore, the authors of this study suspect newer antidepressants for treatment of MDD with an im- proved clinical profile but a higher drug cost would not prove cost-effective in countries where medical care costs are relatively low, such as Colombia. Moreover, drug costs in this study differed markedly from previous published studies. For example, venlafaxine's estimated cost in this study was 300\% higher than in recent research conducted in Brazil (19). This difference was attributed to the presence of generics in Brazil, as opposed to Colombia, where venlafaxine was only available in the brand-name form (Effexor ${ }^{\circledR}$, Wyeth Colombia). In addition, in Brazil, drug costs are regulated by the government and are therefore expected to be somewhat lower than in other South American countries that do not regulate drug prices. As previously discussed, reducing venlafaxine's cost by $50 \%$ would not change the rank order of the cost-effectiveness ratios of the compared drugs. However, the resultant cost-effectiveness ratio of venlafaxine (US\$ 1251 ) would be very similar to those of fluoxetine and amitriptyline, and no drug would emerge as being cost-effective. Therefore, the cost of venlafaxine (in brandname form) had a substantial impact on the results of this study.

Study results indicating amitriptyline is cost-effective is a welcome finding in a developing country such as Colombia. This drug has one of the lowest acquisition prices of all drug treatments for depression, allowing for expanded drug access and thus enabling more individuals to be treated for MDD in countries with budget constraints.

Recommendations for future research include a focus on HRQL aspects of care, which are so important in depression. The indirect costs of care, which can be substantial and are often borne by patients' families, should also be assessed. In addition, more research needs to be done on Colombia's drug policy to determine its impact on health and prosperity. Future studies should also evaluate the cost-effectiveness of other antidepressants that are clinically important in the treatment of MDD and other major illnesses, such as anxiety, obsessive-compulsive disorders, and chronic pain.
This study has several limitations, most of which are inherent to the pharmacoeconomic model. One limitation is the model's 6-month time horizon. While a 6-month time frame is considered "best practice" for pharmacological treatment of first-episode and acute-phase depression, it is well known that MDD may demand a longer treatment period. Another limitation is the fact that the model did not consider treatment adherence, which could have resulted in some variation in the study results. Additional limitations are related to the model inputs derived from the meta-analysis, which consisted of international efficacy data rather than local effectiveness data (local clinical data [i.e., data for Colombian patients] on the effectiveness of antidepressants were unavailable). Effectiveness data are considered preferable for pharmacoeconomic models, as they are less likely to overestimate the treatment effect in actual practice. To mitigate some of these limitations, the study model tried to simulate real-life practice by considering dropouts due to adverse drug reactions or lack of therapeutic efficacy.

\section{Conclusions}

This study found that amitriptyline was cost-effective compared to fluoxetine and venlafaxine in the treatment of MDD in Colombia. It should be noted, however, that the cost of venlafaxine was estimated using only the brand-name form, because generics were not available. As discussed above, these cost-effectiveness results could differ substantially with the presence of generics or drug cost regulation, as in the case of Brazil. Drug cost-effectiveness could also be affected by higher-cost health care. For example, antidepressants with improved clinical efficacy but higher drug cost may prove cost-effective for treatment of MDD in countries with high-cost hospitalization, by avoiding disease-related complications, but not in countries with relatively low-cost medical care, such as Colombia, where drug costs are the main cost driver. 


\section{REFERENCES}

1. Murray CJL, Lopez AD. Alternative projections of mortality and disability by cause 1990-2020: Global Burden of Disease Study. Lancet. 1997;349(9064):1498-1504.

2. Lopez $A D$, Mathers $C D$, Ezzati M, Jamison DT, Murray CJ. Global and regional burden of disease and risk factors, 2001: systematic analysis of population health data. Lancet. 2006;367(9524):1747-57.

3. Kohn R, Levav I, de Almeida JM, Vicente B, Andrade L, Caraveo-Anduaga JJ, et al. Mental disorders in Latin America and the Caribbean: a public health priority. Rev Panam Salud Publica. 2005;18(4-5):229-40.

4. Muñoz RA, McBride ME, Brnabic AJ, López CJ, Hetem LA, Secin R, et al. Major depressive disorder in Latin America: the relationship between depression severity, painful somatic symptoms, and quality of life. J Affect Disord. 2005;86(1):93-8.

5. Gómez-Restrepo C, Bohórquez A, Pinto Masis D, Gil Laverde JFA, Rondón Sepúlveda M, Díaz-Granados N. Prevalencia de depresión y factores asociados con ella en la población colombiana. Rev Panam Salud Publica. 2004;16(6):378-86.

6. Kohn R, Saxena S, Levav I, Saraceno B. The treatment gap in mental health care. Bull World Health Organ. 2004;82(11):858-66

7. Machado M, Iskedjian M, Einarson TR. Quality assessment of published health economic analyses from South America. Ann Pharmacother. 2006;40(5):943-9.
8. Iglesias $\mathrm{CP}$, Drummond MF, Rovira J, NEVALA Project Group. Health-care decision-making processes in Latin America: problems and prospects for the use of economic evaluation. Int J Technol Assess Health Care. 2005;21(1):1-14.

9. Doyle JJ, Casciano J, Arikian S, Tarride JE, Gonzalez MA, Casciano R. A multinational pharmacoeconomic evaluation of acute major depressive disorder (MDD): a comparison of cost-effectiveness between venlafaxine, SSRIs and TCAs. Value Health. 2001;4(1):16-31.

10. American Psychiatric Association. DSMIV-TR: Diagnostic and Statistical Manual of Mental Disorders, Fourth Edition, Text Revision. Washington, DC: American Psychiatric Press; 2000.

11. Hamilton M. A rating scale for depression. J Neurol Neurosurg Psychiatry. 1960;23:56-62.

12. Montgomery SA, Åsberg M. A new depression scale designed to be sensitive to change. Br J Psychiatry. 1979;134:382-9.

13. Einarson TR, Addis A, Iskedjian M. Pharmacoeconomic analysis of venlafaxine in the treatment of major depressive disorder. Pharmacoeconomics. 1997;12(2 Pt 2):286-96.

14. Machado M, Iskedjian M, Ruiz I, Einarson TR. Remission, dropouts and adverse drug reaction rates in major depressive disorder: a meta-analysis of head-to-head trials. Curr Med Res Opin. 2006;22(9):1825-37.

15. Frank E, Prien RF, Jarrett RB, Keller MB, Kupfer DJ, Lavori PW, et al. Conceptualiza- tion and rationale for consensus definitions of terms in major depressive disorder: remission, recovery, relapse, and recurrence. Arch Gen Psychiatry. 1991;48(9):851-5.

16. Colombia, Ministerio de Protección Social. Clasificación de los procedimientos médicos, quirúrgicos y hospitalarios. Manual tarifario SOAT 2005 (Decreto 2423 de 1996). Bogotá: Ministerio de Protección Social. Available from: http://www.minproteccionsocial.gov. co/VBeContent/NewsDetail.asp?ID=13354\& IDCompany=3.

17. Farmácia Cespedes [Internet site]. [Drug price list from local pharmaceutical supplier]. Medellín, Colombia: Farmácia Cespedes; 2007. Available from: http://www.farmaciaces pedes.com/t_208/principal.mv. Accessed 15 April 2007.

18. Lenox-Smith A, Conway P, Knight C. Cost effectiveness of representatives of three classes of antidepressants used in major depression in the UK. Pharmacoeconomics. 2004;22(5): 311-9.

19. Machado M, Iskedjian M, Ruiz I, Einarson TR. The impact of introducing serotoninnoradrenaline reuptake inhibitors in the Brazilian national drug formulary: costeffectiveness and budget-impact analyses. Pharmacoeconomics. 2007;25(11):979-90.

Manuscript received on 25 May 2007. Revised version accepted for publication on 17 April 2008.
RESUMEN

Farmacoeconomía de antidepresivos en trastornos de depresión moderada e intensa en Colombia

Palabras clave
Objetivo. Comparar tres medicamentos antidepresivos de diferentes clases empleados para tratar trastornos depresivos mayores moderados e intensos en adultos colombianos. Métodos. A partir de los aportes de expertos se adaptó un modelo de árbol de decisión para Colombia a fin de analizar los datos de seis meses desde la perspectiva del gobierno como pagador de los servicios. Se determinó la relación costo-efectividad de la amitriptilina, la fluoxetina y la venlafaxina. El desenlace clínico fue la remisión de la depresión (una puntuación $\leq 7$ en la escala de depresión de Hamilton o $\leq 12$ en la escala de valoración de la depresión de Montgomery-Åsberg) después de 8 semanas de tratamiento. Los datos clínicos se obtuvieron de la literatura especializada y los costos, de las listas habituales de precios de Colombia. Se realizaron análisis de sensibilidad simples y multifactoriales para probar la robustez de los modelos.

Resultados. Los costos del tratamiento por paciente (en dólares estadounidenses de 2007) fueron: US\$ 1618 para la venlafaxina, US\$ 1207 para la fluoxetina y US\$ 1068 para la amitriptilina. Las tasas de remisión general fueron $73,1 \%, 64,1 \%$ y $71,3 \%$, respectivamente. La amitriptilina tuvo un menor costo y una mayor remisión que la fluoxetina. La razón de rentabilidad incremental de la venlafaxina sobre la amitriptilina fue de US\$ 31 595. El inductor de costos (cost driver) del modelo fue el valor de adquisición de la venlafaxina, que representó $53,4 \%$ del total del costo por paciente tratado, en comparación con la fluoxetina $(18,5 \%)$ y la amitriptilina $(24,8 \%)$. En los otros casos, la hospitalización representó el mayor costo $(72,1 \%$ y $65,2 \%$, respectivamente). El análisis de sensibilidad probabilístico (Monte Carlo) confirmó los resultados preliminares del modelo farmacoeconómico.

Conclusiones. En Colombia, la amitriptilina es más efectiva en función del costo que la fluoxetina y la venlafaxina. No obstante, el costo de la venlafaxina se estimó a partir del medicamento de marca, ya que no había genéricos disponibles. Esta relación costo-efectividad puede variar considerablemente con la aparición de medicamentos genéricos o medidas regulatorias del costo de los medicamentos.

Economía farmacéutica, agentes antidepresivos, técnicas de apoyo para la decisión, Colombia. 